\title{
The Effect of the Family Empowerment Model on Quality of Life in Children with Chronic Renal Failure: Children's and Parents' Views
}

\author{
Marzieh Sadat Minooei, ${ }^{1}$ Zohreh Ghazavi, ${ }^{2}$ Zahra Abdeyazdan, ${ }^{3}$ Alaleh Gheissari, ${ }^{4}$ and Zeinab \\ Hemati $^{5, *}$ \\ ${ }^{1}$ Department of Nursing, Faculty of Nursing and Midwifery, Najafabad Branch, Islamic Azad University, Najafabad, IR Iran \\ ${ }^{2}$ Nursing and Midwifery Care Research Center, Faculty of Nursing and Midwifery, Isfahan University of Medical Sciences, Isfahan, IR Iran \\ ${ }^{3}$ Department of Pediatric Nursing, Faculty of Nursing and Midwifery, Isfahan University of Medical Sciences, Isfahan, IR Iran \\ ${ }^{4}$ Isfahan Kidney Research Center, School of Medicine, Isfahan University of Medical Sciences, Isfahan, IR Iran \\ ${ }^{5}$ Nursing and Midwifery Care Research Center, Faculty of Nursing and Midwifery, Isfahan University of Medical Sciences, Isfahan, IR Iran \\ "Corresponding author: Zeinab Hemati, Nursing and Midwifery Care Research Center, Faculty of Nursing and Midwifery, Isfahan University of Medical Sciences, Isfahan, IR \\ Iran. Tel: +98-9133838758, E-mail: z_hemate@nm.mui.ac.ir
}

Received 2016 February 02; Revised 2016 March 26; Accepted 2016 June 11.

\section{Abstract}

Background: Chronic renal failure (CRF) causes a gradual decline in kidney function to the extent that CRF patients need long-term clinical care, which affects the patients' family function and quality of life (QoL).

Objectives: The present study was conducted to study the effects of the family-centered empowerment model on QoL in children with CRF during 2012-2013.

Patients and Methods: In this quasi-experimental study, 68 children with CRF and their parents were randomly assigned to two groups, intervention and control, via a random numbers table. An empowerment program was then conducted over the course of seven 45-minute sessions, and a questionnaire to ascertain demographic characteristics and the core pediatric QoL Inventory (version 4) were administered to both groups before the sessions and one month after the last training session. The data were analyzed using SPSS 20.

Results: The mean age of the children was 10.2 and 10.5 years in the intervention and control groups, respectively. The duration of the disease was five years in both groups. Furthermore, a significant difference was seen in the mean score of the children's QoL from their own perspectives in the physical and psychosocial domains and the total QoL score in the intervention group before and after the training $(\mathrm{P}<0.05)$.

Conclusions: Since family-centered empowerment interventions can determine the training-and treatment-related needs of patients and are low cost and effective, they may help parents promote their children's self-efficacy and QoL.

Keywords: Quality of Life, Chronic Renal Failure, Child, Family Empowerment

\section{Background}

Chronic renal failure (CRF) is a destructive and progressive disease that causes disequilibrium in the body's metabolism and water and electrolyte balance (1), and finally leads to a gradual decline in kidney function over a period of three or more months. In children, the condition usually necessitates long-term clinical care in hospitals and the community (2).

According to a report by the third international society for health and nutrition research (3), 26.3 million individuals worldwide are suffering from CRF. The latest epidemiological study of CRF in Iran has projected that over 40,000 individuals will acquire CRF if the current trend of CRF acquisition persists (4). Furthermore, the available data indicate that the number of children with CRF is increasing, such that CRF prevalence has been reported in 18 per 1,000,000 of the global population (1). This disease di- rectly affects the quality of life (QoL) of children and their families (2). QoL refers to a sense of well-being and satisfaction with the domains of an individual's life that are considered significant from his/her perspective $(5,6)$.

Previously, effective treatments and the management of disease symptoms were thought to provide desirable conditions for patients, but research has indicated that QoL is not related only to managing disease symptoms (7). In fact, neglecting QoL can lead to hopelessness, a lack of motivation to make any effort, and a decline in social, cultural, and health-related functions. In other words, enhancing QoL can promote health (8). Furthermore, disease and QoL are reciprocally related, and physical disorders and symptoms can directly affect all domains of QoL (9).

Since CRF is a chronic disease that directly affects the QoL of children and their families, treatment teams should conduct focused interventions to empower families to en- 
hance the QoL and abilities of the family members so that they can overcome the health-related obstacles they are facing. Empowerment refers to the opportunities provided by professionals to family members to improve their existing abilities and competencies and to acquire the new skills required to meet their needs (10). Family empowerment is a process through which the family acquires knowledge and skills so that it can manage family life optimally and consequently enhance the family members' lifestyles and QoL (11). This type of empowerment, which is realized by the interaction between healthcare professionals and families, brings about a sense of control over family life and leads to positive changes that improve the strengths, abilities, and skills of the family (12). Taken together, the aim of the empowerment of an ill child and his/her parents can be to help them deal with and more efficiently manage the disease complications to achieve a higher level of QoL (13).

By emphasizing the fact that CRF causes fundamental changes in families and leads to serious complications, empowerment programs can reduce the cost of hospitalization and the number of absences from school, and improve the physical and psychological functions and achievements of children with CRF. Furthermore, since family-centered empowerment programs are based on educational needs assessments, they may help nurses and physicians offer higher quality healthcare services to children with CRF, leading to peace and the promotion of healthcare-related competencies among these children and their families.

\section{Objectives}

This study was conducted to examine the effects of the family-centered empowerment model on the QoL of children with CRF from both the children's and parents' perspectives.

\section{Patients and Methods}

This quasi-experimental study was conducted from January 2012 to February 2013 (over 13 months). The sample size was 34 children with CRF and their parents in each of two groups (intervention and control) based on similar studies: $\mathrm{d}=. \mid 7 \mathrm{~s} 2, \alpha=0.05, \beta=0.2(14)$. The study was conducted at a pediatric nephrologist's office. Ethical approval for this study was obtained from the research and technology deputy of the Isfahan University of Medical Sciences and the relevant authorities (391138). Children were selected from the office of the pediatric nephrologist by simple random sampling so that the first referring individual with the inclusion criteria was assigned to the intervention group and the second to the control group. This process continued until the desired number of participants was obtained for the two groups.

The inclusion criteria were: age 8-12 years, no previous kidney transplantation, the absence of other chronic diseases, the ability to comprehend the Persian dialect, no mental and psychological problems (by medical file and medical examination), the children's and parents' consent to participate in the study, and the parents' ability to read and write. The exclusion criteria consisted of patient withdrawal from the study, movement, and events such as parents' divorce and the death of the parents and/or siblings.

In this study, the family empowerment model was considered the independent variable, QoL the dependent variable, and the children's age, gender, and education level, and parents' place of residence the underlying variables. After the research purposes were explained to, and written consent was obtained from, the participants in both groups, the researcher administered the questionnaires for the pretest. The training sessions were then planned in coordination with the children and parents in the intervention group, and the pediatric nephrologist's office was judged a suitable location for training and thus used to hold the sessions.

After the questionnaires had been filled out by the two groups, needs assessment sessions were held by the researcher for the intervention group, and the content of the empowerment program was developed after identifying the sources, limitations, and needs of the children and their parents. The content of the empowerment program was validated and confirmed by a number of experienced university teachers.

The codified program was then conducted in accordance with the steps of the empowerment model. Seven 45-minute sessions were carried out with the children based on their needs and tolerance, and three sessions in the form of group discussions were held with the parents. The family empowerment model was implemented in four organized steps. The training content was developed based on the results of the children's and parents' needs assessments, but the steps of the intervention were taken from a study by Alhani et al. (15).

Training was implemented by the researcher in a group and face-to-face using speech, brainstorming, and educational aids, which included powerpoint presentations, movies, and educational replicas.

First step (knowledge enhancement): To enhance knowledge levels, several teaching aids and techniques were used. These included PowerPoint presentations, models, posters, team teaching, question-and-answer ses- 
sions, lecturing, and role-playing. For this, the participants were divided into 4-5 individual subgroups based on the type of disease, and were given teaching materials on kidney physiology and anatomy, etiology, symptoms, disease complications and prognosis, diet, laboratory tests and normal test values, methods of measuring weight, height, and blood pressure, and pharmacotherapy.

Second step (self-efficacy enhancement): To enhance self-efficacy, two sessions comprising demonstrations were held. In this method, explanations regarding the skills required for weight and blood pressure measurement were given, and these skills were taught to the children via demonstrations.

Third step (self-esteem enhancement through participatory training): In this step, the children were asked to encourage their parents to help them and to participate in training their parents to identify CRF-related issues. In this method, the children transferred the knowledge gained via the materials used in each group discussion as well as observation in the self-efficacy sessions to their parents. The children were given teaching cards of the materials for each session and were asked to give them to their parents to study. The parents then wrote down on paper the material from the cards, what they had learned from their children's statements, and the relevant questions they had, and had their children give their written notes to the researcher in the next session.

Since the parents were likely to fail to study the cards, to appropriately understand the teaching materials through their children's training, and hence to acquire adequate competency, the researcher invited them to three 45-minute training sessions on the disease course, diet, physical activity, pharmacotherapy, and disease complications. Two weeks after the last session, the researcher called all the participants to follow up on the implementation of the skills learned and to ensure that the taught materials were being implemented. Furthermore, the participants were given the researcher's telephone number to ask any questions, if necessary.

Fourth step (process evaluation): To evaluate their knowledge, at the beginning of each session, the children were verbally asked some questions about the materials from the previous session. Self-efficacy was evaluated by asking the children to demonstrate or conduct two learned skills appropriately, while self-esteem was assessed by the level of the children's cooperation in the participatory training when giving back the training cards comprising their parents' notes. One month after the last intervention in the intervention group, the questionnaires were again administered to both groups. For ethical reasons, the handbook offered to the intervention group was also offered to the control group after the questionnaires had been filled out

The data gathering instrument consisted of two sections: demographic characteristics and the questionnaire of core pediatric QoL Inventory (version 4). This questionnaire consists of 23 items, eight items for physical function and 15 items for psychosocial function (emotional, social, and school functions, each comprising five items).

The validity and reliability of the Persian version of this questionnaire have already been examined in Iran, and its content validity and Cronbach's alpha were found to be 91.36\% and 0.77, respectively (16). The data were analyzed by descriptive and analytical (chi-square, paired t-test, and independent t-test) statistics in SPSS 20.A P value less than 0.05 was considered statistically significant.

\section{Results}

In this study, the mean age of the children was 10.2 and 10.5 years in the intervention and control groups, respectively. The duration of the disease was 5.5 and 5.1 years, and the age at diagnosis 5.5 and 5.1 years in the intervention and control groups, respectively (Table 1). Furthermore, a significant difference in the mean score of the children's QoL was seen from their own perspectives in the physical and psychosocial domains and the total QoL score in the intervention group before and after the training, but the corresponding difference in the control group was not significant between the two groups before and after the training (Table 2).

For the parents' viewpoints about their children's QoL, the mean QoL scores in the physical and psychosocial domains and the total QoL score in the intervention group were significantly different before and after the training (P $<0.05$ ), but in the control group, no significant difference was seen before and after the training $(\mathrm{P}>0.05)$ (Table 3$)$

\section{Discussion}

This study was conducted to explore the effect of the family empowerment model on the QoL of children with CRF from both the children's and parents' perspectives. The findings indicated that, in the intervention group, the children's QoL from their own perspectives was significantly different in the physical and psychosocial domains and the total QoL score was significantly different before and after the training, but the corresponding difference was not statistically significant in the control group.

Similarly, Mangione-Smith et al. (17) demonstrated that the family-centered empowerment model resulted in an enhancement of knowledge and awareness of disease, a reduction in the number of absences from school and nonemergency referrals, and an overall increase in children's 
Table 1. The Demographic Characteristics of the Children in the Intervention and Control Groups

\begin{tabular}{|c|c|c|c|}
\hline Demographic Variables & Intervention Group & Control Group & P Value \\
\hline Age, $y$, Mean \pm SD & $10.2 \pm 1.5$ & $10 \pm 1.3$ & 0.5 \\
\hline \multicolumn{4}{|l|}{ Sex, No. (\%) } \\
\hline Male & 41.2 & 41.2 & 0.1 \\
\hline Female & 58.8 & 58.8 & \\
\hline \multicolumn{4}{|l|}{ Residential location, \% } \\
\hline City & 70.6 & 94.1 & 0.07 \\
\hline Village & 29.4 & 5.9 & \\
\hline \multicolumn{4}{|l|}{ Educational level of the child, \% } \\
\hline Second & 5.9 & 5.9 & \\
\hline Third & 17.6 & 17.6 & 0.73 \\
\hline Fourth & 11.8 & 23.5 & \\
\hline Fifth & 47.1 & 35.3 & \\
\hline Other & 17.6 & 17.6 & \\
\hline \multicolumn{4}{|l|}{ Father's education, \% } \\
\hline Illiterate & 5.9 & 5.9 & \\
\hline Primary & 17.6 & 17.6 & \\
\hline Secondary & 23.5 & 29.4 & 0.79 \\
\hline Diploma & 35.3 & 17.6 & \\
\hline Associated degree & 5.9 & 0 & \\
\hline BS & 11.8 & 17.6 & \\
\hline$>\mathrm{BS}$ & 0 & 11.8 & \\
\hline \multicolumn{4}{|l|}{ Mother's education, \% } \\
\hline Primary & 11.8 & 5.9 & \\
\hline Secondary & 17.6 & 23.5 & 0.76 \\
\hline Diploma & 47.1 & 41.2 & \\
\hline Associated degree & 11.8 & 5.9 & \\
\hline BS & 5.9 & 5.9 & \\
\hline$>$ BS & 5.9 & 0 & \\
\hline \multicolumn{4}{|l|}{ Father's occupation, \% } \\
\hline Employee & 23.5 & 23.5 & \\
\hline Worker & 41.2 & 11.8 & 0.24 \\
\hline Self-employed & 29.4 & 52.9 & \\
\hline Other & 5.9 & 11.8 & \\
\hline \multicolumn{4}{|l|}{ Mother's occupation, \% } \\
\hline Home maker & 76.5 & 94.1 & 0.15 \\
\hline Employee & 23.5 & 5.9 & \\
\hline Length of disease, $y$, Mean \pm SD & $5.5 \pm 2.9$ & $5.1 \pm 2.5$ & 0.7 \\
\hline Age at disease diagnosis, $y$, Mean \pm SD & $5.05 \pm 2.7$ & $5.5 \pm 2.8$ & 0.6 \\
\hline
\end{tabular}


Table 2. The Mean \pm Standard Deviation of the Children's Quality of Life (QoL) Scores from the Children's Perspectives Before and After Training in the Intervention and Control Groups

\begin{tabular}{|c|c|c|c|}
\hline \multirow[t]{2}{*}{ Time } & \multicolumn{2}{|c|}{ Group } & \multirow{2}{*}{$\begin{array}{c}\text { Pvalue } \\
\text { Independent t-test }\end{array}$} \\
\hline & Intervention & Control & \\
\hline \multicolumn{4}{|l|}{ Before training } \\
\hline Physical & $71.8 \pm 9.7$ & $72.2 \pm 8.5$ & 0.87 \\
\hline Psychosocial & $0.78 \pm 11.1$ & $77.7 \pm 14.9$ & 0.95 \\
\hline \multicolumn{4}{|l|}{ After training } \\
\hline Physical & $79.8 \pm 6.1$ & $70.8 \pm 11.9$ & 0.000 \\
\hline Psychosocial & $84.3 \pm 7.8$ & $76.8 \pm 15.1$ & 0.01 \\
\hline Total QOL score & $83.2 \pm 6.0$ & $75.3 \pm 13.5$ & 0.003 \\
\hline \multirow[t]{2}{*}{ Time } & \multicolumn{2}{|c|}{ Group } & Pvalue \\
\hline & Intervention & Control & Independent t-test \\
\hline \multicolumn{4}{|l|}{ Before training } \\
\hline Physical & $72.1 \pm 18.6$ & $70.3 \pm 16.4$ & 0.67 \\
\hline Psychosocial & $70.2 \pm 0.15$ & $71.6 \pm 16.5$ & 0.72 \\
\hline Total score & $70.7 \pm 14.8$ & $71.3 \pm 14.7$ & 0.87 \\
\hline \multicolumn{4}{|l|}{ After training } \\
\hline Physical & $79.2 \pm 11.8$ & $67.9 \pm 11.5$ & 0.000 \\
\hline
\end{tabular}

activities in school and their communities. Chen and $\mathrm{Li}(18)$ considered empowerment interventions to be effective for the promotion of QoL in patients with chronic diseases.

In light of the findings of several studies and the special status of training in the empowerment model, our findings are not surprising. In their study, Graves and Shelton (19) indicated that empowerment caused positive changes in the children's function and considerable improvements in their behavioral problems. Gerson et al. (20) conducted a study on the QoL of children with CRF and showed that the QoL of these children was significantly lower than that of healthy children. Notwithstanding, Ghazavi et al. (21) showed that the family empowerment model was effective in improving the QoL of children with chronic kidney disease.

Taimori et al.'s (13) study of the effect of the familycentered empowerment model on the QoL of children with asthma demonstrated a significant difference in the QoL between the case and control groups before and after the intervention. In the same way, Borhani et al. (22) indicated in their study that QoL improved across all domains in the case group of school-aged children with thalassemia compared to the control group after implementing the familycentered empowerment model.

The aforementioned findings could be explained by the fact that the specific steps in the empowerment model cause children to engage with and participate actively in the process. Furthermore, promoting the children's selfefficacy and improving their self-confidence by increasing their participatory training helped to enhance the QoL of the children in the intervention group in this study. Additionally, given the use of different training methods and a wide range of materials based on the children's levels of understanding, their QoL was likely to improve across all domains.

This study also indicated that the QoL of the children in the intervention and control groups was significantly different across all domains from their parents' perspec- 
tives. Similarly, a study of QoL in children with CRF from the children's and their parents' perspectives indicated a significant difference in QoL scores across all domains between the children and their parents (23). Alavi et al. (24) likewise compared the QoL between children and adolescents with diabetes and healthy children from their own and their parents' perspectives, and demonstrated a significant difference in the total QoL scores in the physical, emotional, and social domains between the parents with healthy children and those with diabetic children. In a study of the child-parent difference in reporting QoL in adolescents with chronic disease, the adolescents reported a significantly lower QoL for themselves than the QoL their parents indicated for their children (25).

Since the children in this training program were responsible for teaching their parents, they were motivated to participate actively, leading to enhanced self esteem, which could be explained by their significant contribution to their own and their parents' learning. Moreover, having the parents attend the training sessions simultaneously with their children, which was a strength of this study, could have contributed greatly to improving the QoL of the children in the intervention group.

A limitation of the present study was the individual characteristics that could have influenced the children's perceptions of QoL. Each child's interest in adopting the method, their particularities, and their emotional and psychological traits as well as their own and their parents' cultural roots could have affected their QoL perceptions. These factors were not controlled for in the present study.

\subsection{Conclusion}

Given the findings of this study, implementation of the family empowerment model could help children with CRF and their parents identify their deficiencies and feel capable enough to change their existing conditions. This model is therefore also recommended for use as a healthcare intervention for children with other chronic diseases to empower such children and their parents and promote their healthcare-related function.

\section{Acknowledgments}

We are most grateful to all the children and parents who participated in this study.

\section{Footnote}

Funding/Support: Isfahan University of Medical Sciences.

\section{References}

1. Beaulieu M, Levin A. Analysis of multidisciplinary care models and interface with primary care in management of chronic kidney disease. Semin Nephrol. 2009;29(5):467-74. doi: 10.1016/j.semnephrol.2009.06.003. [PubMed: 19751891].

2. Behrman R, Kligman E, Robert M, Bonita F. Nelson text book of pediatrics. 19 ed. Elsevier: Saunders; 2008. pp. 1822-5.

3. Clase CM, Kiberd BA, Garg AX. Relationship between glomerular filtration rate and the prevalence of metabolic abnormalities: results from the Third National Health and Nutrition Examination Survey (NHANES III). Nephron Clin Pract. 2007;105(4):178-84. doi: 10.1159/000100489. [PubMed: 17347576].

4. Nafar M, Mousavi SM, Mahdavi-Mazdeh M, Pour-Reza-Gholi F, Firoozan A, Einollahi B, et al. Burden of chronic kidney disease in Iran: a screening program is of essential need. Iran J Kidney Dis. 2008;2(4):183-92. [PubMed: 19377235].

5. Hemati Z, Kiani D , Mosavi F. Comparison of the quality of life among patients with idiopathic thrombocytopenic purpura and healthy people in isfahan. Iranian J Blood Cancer. 2014;7(1):31-6.

6. Moradian Sorkhkolaee M, Esmaeili Shahmirzadi S, Sadeghi R, Nikooseresht Z, Fard F. The relationship between quality of life and social capital among health workers in medical and health network of Rey city in 2012. Razi J Med Sci. 2013;20(114):69-77.

7. Pakpour A, Panahi Ch D, Yekaninejad M, Ebadi Fard Azar F, Izy H. A comparative study on health related quality of life in hemodialysis patients and healthy people. J Health Administration. 2006;9(25):5562.

8. Heidari M, Alhani F, Kazemnejad A, Moezzi F. The effect of empowerment model on quality of life of diabetic adolescents. Iran J Pediatr. 2007;17(Suppl 1):87-94.

9. Hemate Z, Alidosti M, Golchin M. A comparative different aspects quality of life in health adolescents with hemophilia adolescents referred to seyed al-shohada hospital in isfahan 2011. Sci J Iran Blood Transfus Organ. 2012;9(3):331-6.

10. Wilson D, Wong DL, Hockenberry MJ. Wong's nursing care of infants and children. Mosby/Elsevier; 2011.

11. Subandi MA. The role of family empowerment and family resilience on recovery from psychosis. Gadjah Mada University; 2013.

12. Lauritsen CB, Kokckrow EO. Foundations And Adult Health Nursing. 5 ed. Mosby; 2006.

13. Teymouri F, Alhani F, Kazemnejad A. The effect of family-centered empowerment model on the quality of life of school-age asthma children. Sci j Hamedan nursing midwifery faculty. 2014;22(3):5-14.

14. Hemati Z, Abasi S, Mosaviasl F, Shakerian B, Kiani D. Effect of Orem's Self-Care Model on Self-Esteem of Adolescents with Asthma Referred to an Asthma and Allergy Clinic in Isfahan. Tanaffos. 2015;14:232-7.

15. Alhani F. Design and evaluation of family centered model of empowerment in the prevention of iron deficiency anemic. Tarbiat Modarres University; 2004

16. Borhani F, Najafi MK, Rabori ED, Sabzevari S. The effect of familycentered empowerment model on quality of life of school-aged children with thalassemia major. Iran J Nurs Midwifery Res. 2011;16(4):2928. [PubMed: 23450080].

17. Mangione-Smith R, Schiff J, Dougherty D. Identifying children's health care quality measures for Medicaid and CHIP: an evidenceinformed, publicly transparent expert process. Acad Pediatr. 2011;11(3 Suppl):11-21. doi: 10.1016/j.acap.2010.11.003. [PubMed: 21570013].

18. Chen YC, Li I-C. Effectiveness of interventions using empowerment concept for patients with chronic disease: A systematic review. JBI Database System Rev Implement Rep. 2009;6(12):1179-233.

19. Graves KN, Shelton TL. Family empowerment as a mediator between family-centered systems of care and changes in child functioning: Identifying an important mechanism of change. I Child Fam Stud. 2007;16(4):556-66. doi: 10.1007/s10826-006-9106-1. 
20. Gerson AC, Wentz A, Abraham AG, Mendley SR, Hooper SR, Butler RW, et al. Health-related quality of life of children with mild to moderate chronic kidney disease. Pediatrics. 2010;125(2):349-57. doi: 10.1542/peds.2009-0085. [PubMed: 20083528].

21. Ghazavi Z, Minooei MS, Abdeyazdan Z, Gheissari A. Effect of family empowerment model on quality of life in children with chronic kidney diseases. Iran J Nurs Midwifery Res. 2014;19(4):371-5. [PubMed: 25183977].

22. Borhani F, Kargar Najafi M, Rabori ED, Sabzevari S. The effect of familycentered empowerment model on quality of life of school-aged children with thalassemia major. Iranian $j$ nursing midwifery rese. 2011;16(4).

23. Kilis-Pstrusinska K, Medynska A, Chmielewska IB, Grenda R, Kluska-
Jozwiak A, Leszczynska B, et al. Perception of health-related quality of life in children with chronic kidney disease by the patients and their caregivers: multicentre national study results. Qual Life Res. 2013;22(10):2889-97. doi: 10.1007/s11136-013-0416-7. [PubMed: 23595412].

24. Alavi A, Parvin N, Salehian T, Samipoor V. Assessment of the quality of life of children and adolescents with type 1 diabetes: Child and parental views. Sci J Kurdistan Unive Med Sci. 2010;15(1):46-52.

25. Sattoe JN, van Staa A, Moll HA, On Your Own Feet Research G. The proxy problem anatomized: child-parent disagreement in health related quality of life reports of chronically ill adolescents. Health Qual Life Outcomes. 2012;10:10. doi:10.1186/1477-7525-10-10. [PubMed: 22276974]. 